\title{
Tumor perfusion increases during hypofractionated short-course radiotherapy in rectal cancer: Sequential perfusion-CT findings
}

Citation for published version (APA):

Janssen, M. H. M., Aerts, H. J. W. L., Kierkels, R. G. J., Backes, W. H., Ollers, M. C., Buijsen, J., Lambin, P., \& Lammering, G. (2010). Tumor perfusion increases during hypofractionated short-course radiotherapy in rectal cancer: Sequential perfusion-CT findings. Radiotherapy and Oncology, 94(2), 156160. https://doi.org/10.1016/j.radonc.2009.12.013

Document status and date:

Published: 01/02/2010

DOI:

10.1016/j.radonc.2009.12.013

Document Version:

Publisher's PDF, also known as Version of record

Document license:

Taverne

Please check the document version of this publication:

- A submitted manuscript is the version of the article upon submission and before peer-review. There can be important differences between the submitted version and the official published version of record.

People interested in the research are advised to contact the author for the final version of the publication, or visit the DOI to the publisher's website.

- The final author version and the galley proof are versions of the publication after peer review.

- The final published version features the final layout of the paper including the volume, issue and page numbers.

Link to publication

\footnotetext{
General rights rights.

- You may freely distribute the URL identifying the publication in the public portal. please follow below link for the End User Agreement:

www.umlib.nl/taverne-license

Take down policy

If you believe that this document breaches copyright please contact us at:

repository@maastrichtuniversity.nl

providing details and we will investigate your claim.
}

Copyright and moral rights for the publications made accessible in the public portal are retained by the authors and/or other copyright owners and it is a condition of accessing publications that users recognise and abide by the legal requirements associated with these

- Users may download and print one copy of any publication from the public portal for the purpose of private study or research.

- You may not further distribute the material or use it for any profit-making activity or commercial gain

If the publication is distributed under the terms of Article $25 \mathrm{fa}$ of the Dutch Copyright Act, indicated by the "Taverne" license above, 
Functional imaging

\title{
Tumor perfusion increases during hypofractionated short-course radiotherapy in rectal cancer: Sequential perfusion-CT findings
}

\author{
Marco H.M. Janssen a,*, Hugo J.W.L. Aerts ${ }^{a}$, Roel G.J. Kierkels ${ }^{a, b}$, Walter H. Backes ${ }^{c}$, Michel C. Öllers ${ }^{a}$, \\ Jeroen Buijsen ${ }^{\mathrm{a}}$, Philippe Lambin ${ }^{\mathrm{a}, 1}$, Guido Lammering ${ }^{\mathrm{a}, 1}$ \\ ${ }^{a}$ Department of Radiation Oncology (MAASTRO), Maastricht University Medical Center (MUMC+), Maastricht, The Netherlands; ${ }^{\mathrm{b}}$ Department of Radiation Oncology, \\ University Medical Center Groningen, University of Groningen, Groningen, The Netherlands; ' ${ }^{\mathrm{C}}$ Department of Radiology, Maastricht University Medical Center (MUMC+), \\ Maastricht, The Netherlands
}

\section{A R T I C L E I N F O}

\section{Article history:}

Received 16 October 2009

Received in revised form 13 December 2009

Accepted 20 December 2009

Available online 18 January 2010

\section{Keywords:}

Perfusion-CT

Pharmacokinetic modeling

Rectal cancer

Tumor perfusion

Short-course hypofractionated radiotherapy

\begin{abstract}
A B S T R A C T
Purpose: The purpose of this study was to investigate perfusion of rectal tumors and to determine early responses to short-course hypofractionated radiotherapy (RT).

Material and methods: Twenty-three rectal cancer patients were included, which underwent perfusionCT imaging before (pre-scan) and after treatment (post-scan). Contrast-enhancement was measured in tumor and muscle tissues and in the external iliac artery. Perfusion was quantified with three pharmacokinetic parameters: $K^{\text {trans }}, v_{e}$ and $v_{p}$. Perfusion differences between tumor and normal tissue and changes of the pharmacokinetic parameters between both scans were evaluated.

Results: The median tumors $K^{\text {trans }}$ values increased significantly from the pre-scan $\left(0.36 \pm 0.11\left(\mathrm{~min}^{-1}\right)\right)$ to the post-scan $\left(0.44 \pm 0.13\left(\mathrm{~min}^{-1}\right)\right)(p<0.001)$. Also, histogram analysis showed a shift of tumor voxels from lower $K^{\text {trans }}$ values towards higher $K^{\text {trans }}$ values. Furthermore, the median $K^{\text {trans }}$ values were significantly higher for tumor than for muscle tissue on both the pre-scan $\left(0.10 \pm 0.05\left(\min ^{-1}\right), p<0.001\right)$ and the post-scan $\left(0.10 \pm 0.04\left(\mathrm{~min}^{-1}\right), p<0.001\right)$. In contrast, no differences between tumor and muscle tissues were found for $v_{e}$ and $v_{p}$. Also, no significant differences were observed for $v_{e}$ and $v_{p}$ between the two pCT-imaging time-points.

Conclusions: Hypofractionated radiotherapy of rectal cancer leads to an increased tumor perfusion as reflected by an elevated $K^{\text {trans }}$, possibly improving the bioavailability of cytotoxic agents in rectal tumors, often administered early after radiotherapy treatment.
\end{abstract}

(c) 2009 Elsevier Ireland Ltd. All rights reserved. Radiotherapy and Oncology 94 (2010) 156-160
Radiotherapy (RT), alone or with chemotherapy, is an established treatment for patients diagnosed with rectal cancer [1-3]. In tumors judged to be resectable, pre-operative RT is primarily used to lower the risk of local failure [4-6]. For this purpose, short-course hypofractionated RT $(5 \times 5 \mathrm{~Gy})$ followed by immediate surgery has been extensively used. However, several trial initiatives are currently ongoing to modulate the schedule of shortcourse hypofractionated RT from immediate surgery to a planned delay before surgery with the possible advantage of tumor down-sizing. Further knowledge of the biological changes of the tumor during short-course RT would be useful to optimize the treatment management and to improve the development of response predictors, allowing individualized treatment.

\footnotetext{
* Corresponding author. Address: Department of Radiation Oncology (MAASTRO), Maastricht University Medical Center (MUMC+), GROW-School for Oncology and Developmental Biology, Dr. Tanslaan 12, 6201 BN Maastricht, Box 1588, Maastricht, The Netherlands.

E-mail address: marco.janssen@maastro.nl (M.H.M. Janssen).

1 These authors contributed equally to this paper.
}

Perfusion Computed-Tomography (pCT) imaging is increasingly used in clinical studies as a non-invasive technique to assess the microvascular status of tumor tissue [7-13]. pCT-imaging is a dynamic imaging technique, which can give insight in the uptake kinetics of the administered tracer by pharmacokinetic modeling [14]. A for pCT-imaging commonly applied pharmacokinetic twocompartment model for perfusion imaging is the extended Ketymodel, with the following pharmacokinetic parameters: the transendothelial volume transfer constant $K^{\text {trans }}$, the fractional volume of the extravascular-extracellular space (EES) $\left(v_{e}\right)$ and the fractional blood plasma volume $v_{p}[14,15]$. For cancer research, $K^{\text {trans }}$, describing the transfer rate of the contrast agent from the blood plasma into the EES, is the most valuable pharmacokinetic parameter, related to the microvascular blood flow, vessel wall permeability and vessel density [14].

pCT-measurements have been shown to serve as early markers of treatment response $[9-12,16]$. Tumors with a high $K^{\text {trans }}$ tend to better respond to chemotherapy and/or radiotherapy treatment than tumors with lower values of $K^{\text {trans }}$, blood volume and/or blood flow [9-12,16-18]. However, little is known about therapy-related 
changes of the perfusion parameters of tumor tissue. Wang et al. presented the predictive strength of repeated pCT-imaging, with a decrease of the permeability being predictive for a higher progression-free survival period in non-small cell lung cancer patients treated with chemotherapy [12].

To the best of our knowledge, no study has yet examined early changes in tumor perfusion in response to radiotherapy treatment of rectal cancer.

The purpose of this study was to investigate perfusion of rectal tumors and responses to hypofractionated short-course RT. This could give important insight into early changes in the tumor microcirculation during radiotherapy and might help to better predict tumor response.

\section{Material and methods}

\section{Patient characteristics}

Twenty-three patients, diagnosed with non-locally advanced rectal cancer (NLARC), were included in this study. Based on pretreatment magnetic resonance imaging (MRI), the clinical TNM staging was staged as T I-III, N 0-II, M 0-I. All patients were referred to pre-operative treatment with short-course RT, 5 fractions of $5 \mathrm{~Gy}$ on five consecutive working days, followed by a total mesorectal excision (TME) within 3 days after the last RT fraction. According to the Dutch law, the medical ethics committee approved the trial and all patients gave written informed consent before entering the study.

\section{PET-CT and pCT acquisition}

All patients underwent FDG-PET-CT and pCT-imaging at two time-points: prior to the start of therapy and at the day of the last RT fraction. All PET-CT and PCT examinations were performed on the same dedicated Siemens TruePoint Biograph 40 PET-CT simulator (Siemens Medical, Erlangen, Germany). The patients were positioned equal to the radiotherapy treatment position using a laser alignment system to have minimal variations between imaging and treatment conditions and between the two imaging timepoints. For the PET-CT scan, an intravenous injection of FDG (weight $[\mathrm{kg}]^{*} 4+20 \mathrm{MBq}$ ) was performed. For PET reconstruction (OSEM2D: four iterations, eight subsets), CT-based attenuation correction; 3D scatter- and decay-correction were performed. After the PET-CT scan, a pCT-scan was performed over $100 \mathrm{~s}$. The volume of interest (VOI) for the pCT-scan was defined by an expert radiation oncologist (J.B. or G.L.) with knowledge of the PET-data. To ensure that the most representative tumor area was chosen, the tumor area with the highest FDG-uptake on the PET-scan was se- lected. Knowledge of the FOV selected for the first pCT-scan was used to select the identical region for the second pCT-scan.

For the pCT-scan, a volume of 120 of an iodinated contrast agent (300 mg iodine/mL, Xenetix 300, Guerbet, Aulnay-sous-Bois, France) was injected at a rate of $3 \mathrm{~mL} / \mathrm{s}$ via an automatic injector (Stellant Sx, CT Injection System, MedRad, Warrendale, USA) into the antecubital fossa.

The pCT-scan was performed in a static cine-mode over 12 contiguous slices with a slice thickness of $2.4 \mathrm{~mm}$, a field-of-view of $500 \mathrm{~mm}$ and an image size of $512 \times 512$ pixels. Other acquisition settings were: tube voltage $80 \mathrm{kVp}$, tube current $140 \mathrm{mAs}$ and a rotation time of $1 \mathrm{~s}$

\section{Pharmacokinetic analysis}

Automatic image-registration between the static PET-CT scan and the pCT-scan was performed based on mutual-information (Focal software, version 4.34, CMS Inc., St. Louis, Missouri). For each PET-CT scan, the tumor was delineated with dedicated software (TrueD VC50, Siemens MI, Erlangen, Germany) using automated SUV-thresholding of the PET-images with the threshold (percentage of $\mathrm{SUV}_{\max }$ within the tumor) depending on the tumor-to-background signal ratio, with the gluteus muscle selected as relevant background tissue $[19,20]$. As a reference sample for the pharmacokinetic analysis, an additional VOI was manually selected within the gluteus muscle to check for possible changes of the pharmacokinetic parameters of muscle tissue outside the irradiated volume. When quantifying the pharmacokinetic parameters of muscle tissue, a VOI was manually drawn within both the left and right gluteus muscle. The median values of the pharmacokinetic parameters within both VOIs were averaged to account for intra-tissue heterogeneity of the muscle tissue. The resulting contours of both tumor and muscle tissues were projected on the registered pCT. The pCT-data were down-sampled from a voxel size of $0.98 \times 0.98 \times 2.4 \mathrm{~mm}$ to $3.92 \times 3.92 \times 4.8 \mathrm{~mm}$ to improve the signal-to-noise ratio (SNR). For the quantification of the dynamic pCTdata, the extended Kety-model was used, describing the uptake of a contrast agent from the blood plasma into the tissue by [14]:

$C_{t}(t)=v_{p} C_{p}(t)+K^{\text {trans }} \int_{0}^{t} C_{p}(u) e^{-\frac{-K^{\text {trans }}}{v_{e}}(t-u)} d u$

The blood plasma concentration curve $\left(C_{p}\right)$, extracted from the right external iliac artery, was derived from the acquired whole blood tracer concentration $\left(C_{b}\right)$ divided by $(1-\mathrm{Hct})$, with the hematocrit value (Hct) set to 0.45 (Fig. 2) [14]. To improve the SNR, $C_{p}$ was calculated by averaging the concentration time curves over all voxels selected inside the iliac artery. The tumor and muscle tissue concentration curves $\left(C_{t}\right)$ were extracted from the dynamic

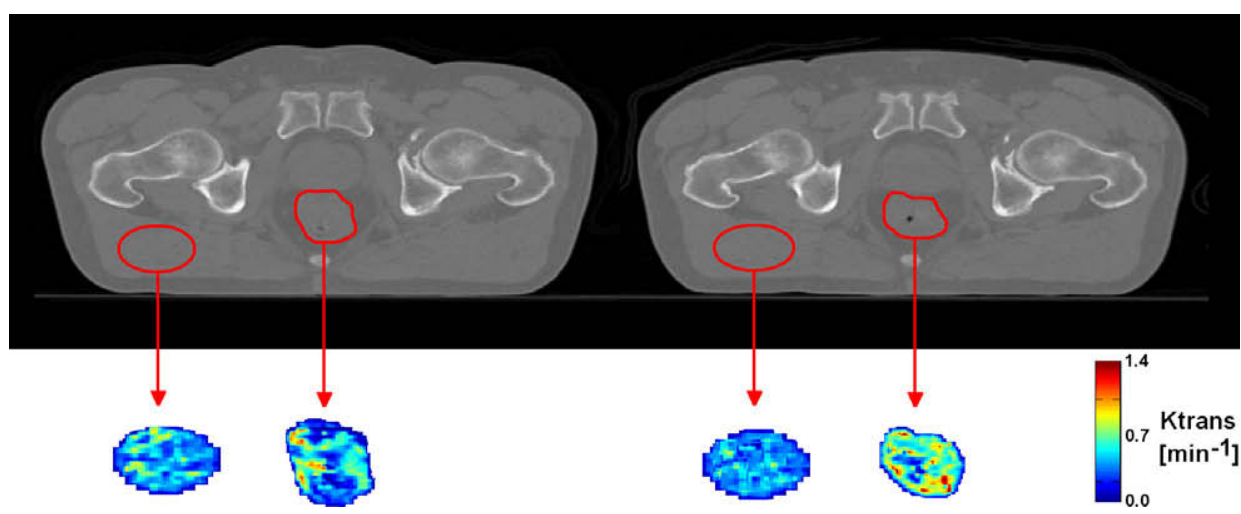

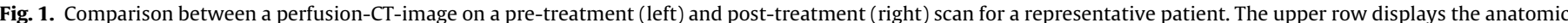

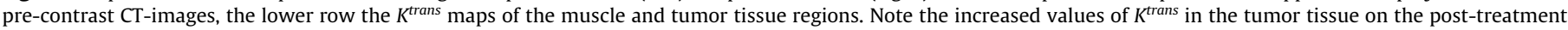
scan compared to the pre-treatment scan. In contrast, muscle tissue presented with similar pattern of $K^{\text {trans }}$ at both time-points. 
Tumor Tissue
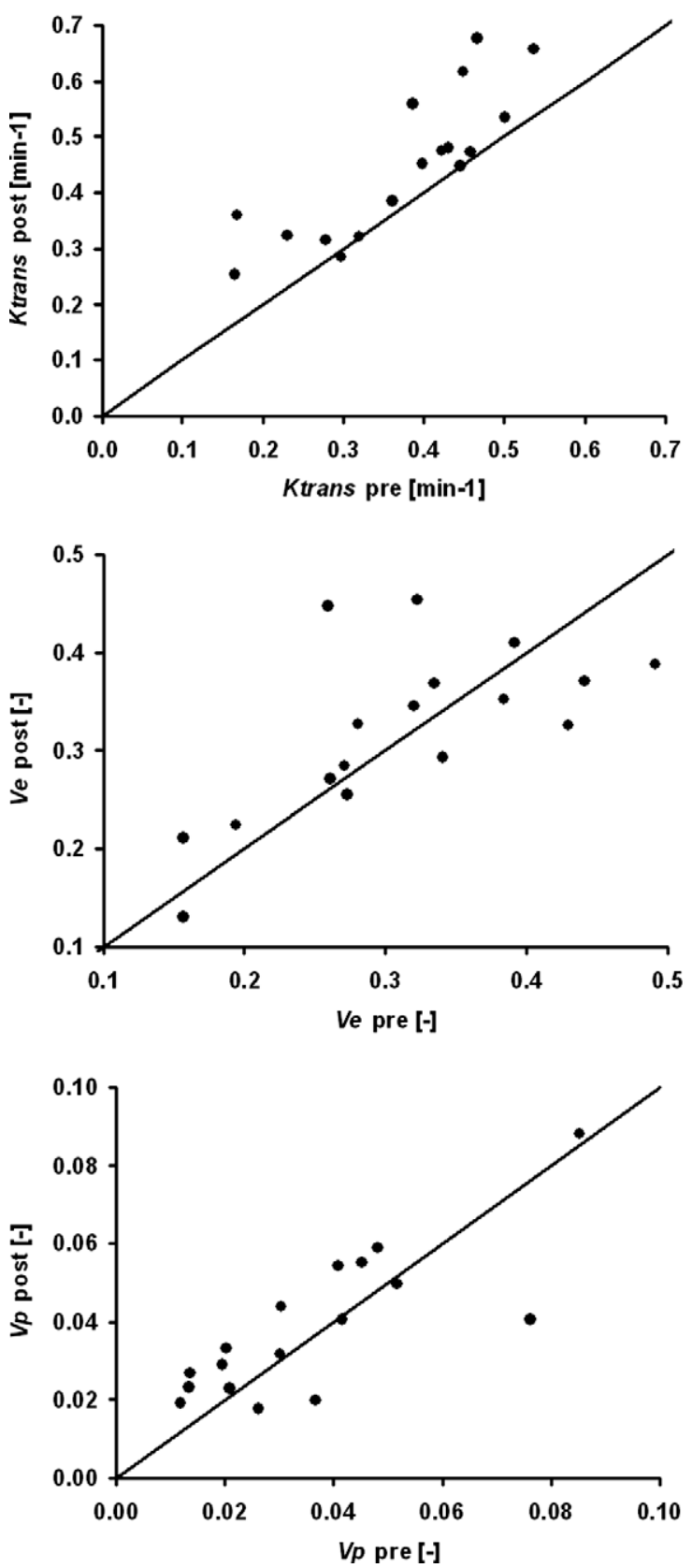

Muscle Tissue
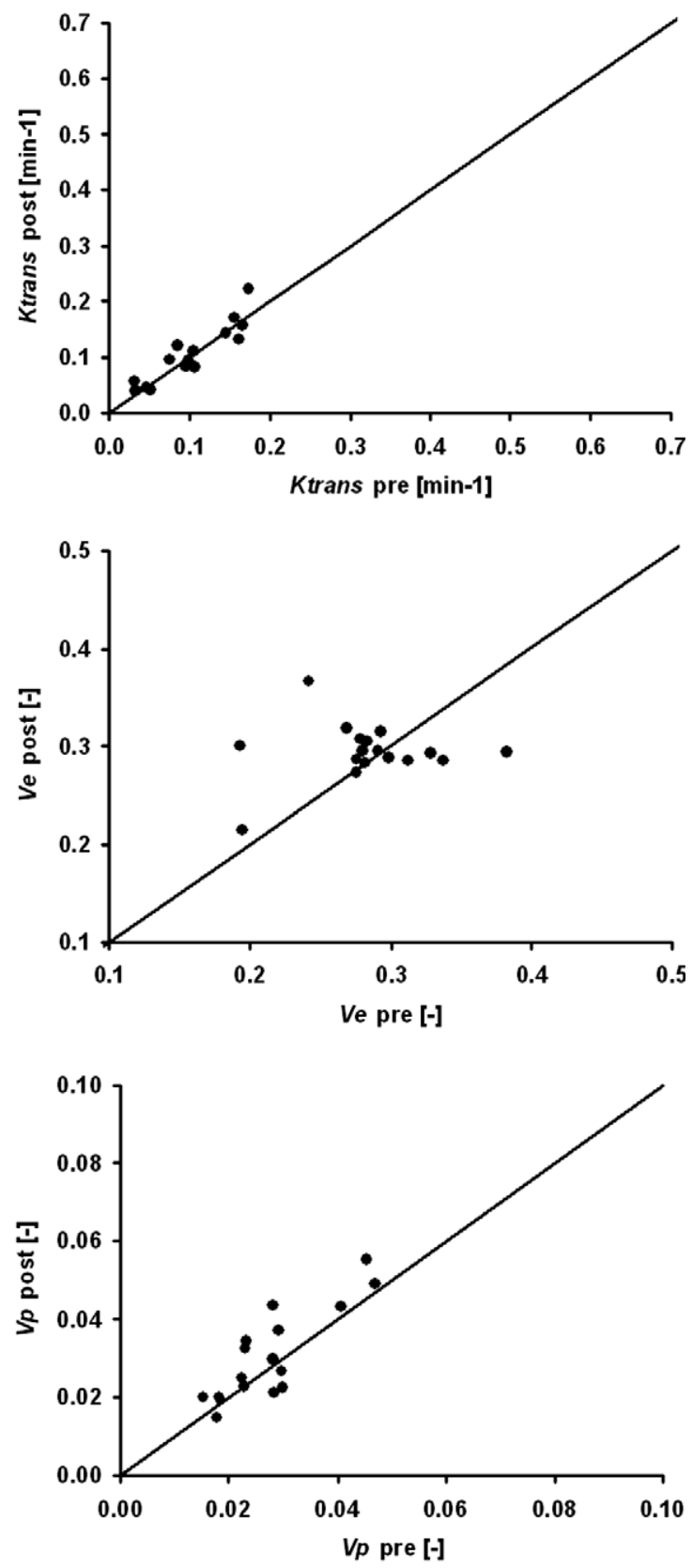

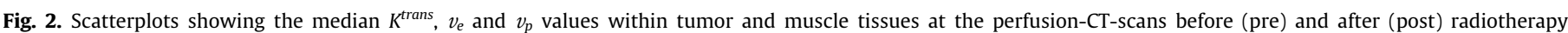

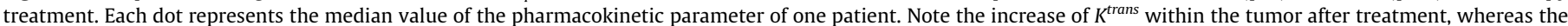
median $K^{\text {trans }}$ values of muscle tissue outside of the irradiated volume remained stable.

pCT-data on a voxel-by-voxel basis and on a tumor uptake curve based on the average of all tumor voxels (Fig. 2). Pharmacokinetic analysis was performed using in-house developed software in MATLAB (R2008b, The Mathworks Inc., Natick, USA). The concentration time curves from pCT-data were fitted to the pharmacokinetic model, with the pharmacokinetic parameters being calculated using the Levenberg-Marquardt algorithm, with boundaries set to $0 \leqslant K^{\text {trans }} \leqslant 5 \mathrm{~min}^{-1}, 0 \leqslant v_{e} \leqslant 1$ and $0 \leqslant v_{p} \leqslant 1[21-23]$.

\section{Statistical analysis}

All data are expressed as means \pm standard deviation (SD) and range. Statistical differences between the parameters were evalu- ated in SPSS (version 15.0, SPSS Inc., Chicago, IL, USA), performing a Wilcoxon-signed-rank test for the comparison of related measurements. Differences were considered to be significant when the $p$-value was less than 0.05 .

\section{Results}

\section{Perfusion of tumor and muscle tissues}

To study differences in the perfusion of tumor and normal tissue, 23 patients diagnosed with rectal cancer underwent sequential pCT-imaging before and after treatment. From these scans, the pharmacokinetic parameters of tumor and normal tissue were calculated at both imaging time-points. In Fig. 1, CT-images of a 
representative patient are shown with the perfusion $K^{\text {trans }}$ maps of both tumor and muscle tissues at both time-points. Visual interpretation of the $K^{\text {trans }}$ maps showed a higher and more heterogeneous uptake in tumor tissue compared to muscle tissue on both scans. Note the increased $K^{\text {trans }}$ in tumor tissue on the post-treatment scan compared to the pre-treatment scan, whereas $K^{\text {trans }}$ in muscle tissue presented similar patterns at both imaging timepoints.

\section{Perfusion parameters before and after short-course radiotherapy}

For the quantification of the pharmacokinetic parameters, the median $K^{\text {trans }}, v_{e}$ and $v_{p}$ values of tumor and muscle tissues were calculated at both time-points. Fig. 2 shows scatterplots of the median parameter values for tumor and muscle tissues. After RT, an increase of the median $K^{\text {trans }}$ within the tumor was found for all patient except one, resulting in an average increase of $K^{\text {trans }}$ of $25.4 \pm 28.7 \%$ (range: $-3.8-113.1 \%)(p<0.001)$. However, the median $K^{\text {trans }}$ values within the muscle tissue was not significantly different between the two imaging time-points $(p=0.554)$. The other two pharmacokinetic parameters, $v_{e}$ and $v_{p}$, showed no significantly different values between the two time-points and between tumor and muscle tissues. In Table 1 , an overview of all median parameter values is shown with the corresponding statistics.

In Fig. 3, the average histogram of the $K^{\text {trans }}$ values within the tumor is shown for all patients. As can be seen from the histogram, pre-operative treatment with short-course hypofractionated RT resulted in an increased tumor perfusion for the included patients.

For the bins of the histogram presenting the number of voxels with a relatively high $K^{\text {trans }}$ value, an increase of the number of voxels was observed between the pre- and post-treatment pCT-scan. In contradiction, a decrease was found for the number of voxels in the bins with a lower $K^{\text {trans }}$ value. The shift of the histogram towards increased bins with relatively higher $K^{\text {trans }}$ indicates an increase of tumor perfusion due to pre-operative treatment with short-course hypofractionated RT.

\section{Discussion}

The purpose of this study was to characterize changes of tumor perfusion after short-course hypofractionated radiotherapy treatment. The pharmacokinetic parameters of rectal tumors revealed significant higher $K^{\text {trans }}$ values compared to muscle tissue at both the pre- and post-treatment pCT-scan. Short-course RT resulted in a significant increase of the median $K^{\text {trans }}$ in tumor tissue, indicating an early increase in tumor perfusion already on the last day of pre-operative RT. The significant increase of tumor perfusion during the rather short time interval between the pre- and posttreatment pCT-scan could be explained by first endothelial cell death within the irradiated volumes, resulting in endothelial cell leakage which in turn results in increased values of $K^{\text {trans }}$ within

Table 1

Overview of the median pharmacokinetic parameters, $K^{\text {trans }}, v_{e}$ and $v_{p}$, in tumor and muscle tissues both pre- and post-treatment.

\begin{tabular}{lllll}
\hline & & Pre-RT & Post-RT & $p$-value \\
\hline$K^{\text {trans }}\left(\mathrm{min}^{-1}\right)$ & Tumor tissue & $0.36 \pm 0.11$ & $0.44 \pm 0.13$ & $<0.001$ \\
& Muscle tissue & $0.10 \pm 0.05$ & $0.10 \pm 0.05$ & 0.554 \\
& $p$-value & $<0.001$ & $<0.001$ & \\
$v_{e}(-)$ & Tumor tissue & $0.31 \pm 0.10$ & $0.32 \pm 0.09$ & 0.795 \\
& Muscle tissue & $0.28 \pm 0.05$ & $0.29 \pm 0.03$ & 0.381 \\
& $p$-value & 0.356 & 0.344 & \\
$v_{p}(-)$ & Tumor tissue & $0.04 \pm 0.02$ & $0.04 \pm 0.02$ & 0.124 \\
& Muscle tissue & $0.03 \pm 0.01$ & $0.03 \pm 0.01$ & 0.098 \\
& $p$-value & 0.266 & 0.266 & \\
\hline
\end{tabular}

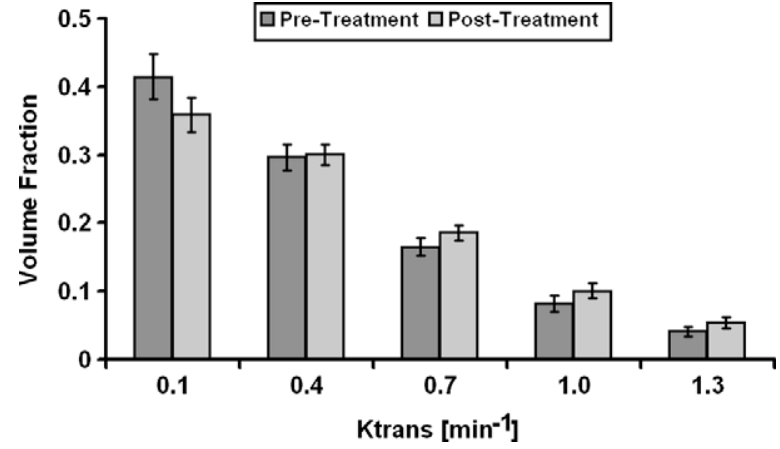

Fig. 3. Histogram of the $K^{\text {trans }}$ values within the tumor for all of the included patients on the pre-treatment scan (dark boxes) and post-treatment scan (light boxes). The bars represent the mean and the error-bars the standard deviation of the $K^{\text {trans }}$ estimates within the bin. Note the increase of the number of voxels within the bins with a higher $K^{\text {trans }}$ value $(>0.4)$ after pre-operative treatment with shortcourse hypofractionated radiotherapy, indicating an increase of tumor perfusion after radiotherapy treatment.

the tumor. The VOI manually selected within muscle tissue was chosen outside of the irradiated volume, so no endothelial cell death was expected to occur within the VOIs of muscle tissue. An increase in tumor perfusion early during pre-operative treatment might improve the availability of cytotoxic agents of chemotherapy to the tumor, often administered after finishing the radiotherapy treatment. The data as presented within this study could serve as reference data of perfusion changes within the tumor during RTtreatment for future studies combining a short-course hypofractionated radiotherapy course with anti-angiogenic agents (e.g., rapamycin).

In general, perfusion measurements are intrinsically variable due to internal and external factors, including day-to-day physiological variations, technical variability, observer variability and intra-tissue heterogeneity [24]. The used acquisition time of $100 \mathrm{~s}$ was long enough to perform measurements of $K^{\text {trans }}$, whereas measurements of $v_{e}$ require imaging times which incorporate the maximal signal enhancement in the tumor tissue, about 120-180 s after injection of the contrast agent $[25,26]$. For this reason, the relatively short imaging time used within this study might bias the $v_{e}$ values measured within this study. The used sampling time of $1 \mathrm{~s}$ was expected to be sufficient for reliable estimations of both $K^{\text {trans }}$ and $v_{p}[15,26]$.

One of the major limitations of this study was the relatively small dimension of the FOV of the pCT-scan in craniocaudal direction. The craniocaudal coverage of the pCT FOV of only $2.88 \mathrm{~cm}$ resulted for some patients in an incomplete coverage of the rectal tumor. For these patients, pCT-measurements were obtained from the tumor region showing the highest FDG-uptake, as assessed from the static PET-CT scan. Due to incomplete tumor coverage, the calculated median values of the three investigated pharmacokinetic parameters only represent the perfusion of the tumor region covered by the FOV. However, Goh et al. presented a study showing that an increased FOV in craniocaudal direction does not improve the reproducibility of perfusion measurements [27]. Another limitation was that day-to-day differences in bladder and rectum filling, hampering a voxel-wise comparison of the pharmacokinetic parameter maps of the pre- and post-treatment pCT-scans within this study. Due to large differences in bladder or rectum filling for some of the included patients, a rigid registration was not sufficient to enable a correct registration of the preand post-treatment pCT-scans. However, available non-rigid registration algorithms are not yet properly validated for rectal cancer.

In conclusion, perfusion-CT measurements of rectal tumors enable the assessment of changes of tumor perfusion resulting from 
radiotherapy treatment. Short-course hypofractionated radiotherapy of rectal cancer significantly increased tumor perfusion $\left(K^{\text {trans }}\right)$, which might improve the bioavailability of cytotoxic agents in rectal tumors, often administered to the patient after radiotherapy treatments.

\section{Acknowledgements}

The authors acknowledge the financial support from the Netherlands Organization for Health Research and Development (ZonNW; clinical fellowship awarded to G.L.) and the Dutch Cancer Society (KWF: fellowship granted to H.J.W.L.A.). We also acknowledge technical and financial support from Siemens MI.

\section{References}

[1] Frykholm G, Glimelius B, Pahlman L. Preoperative irradiation with and without chemotherapy (MFL) in the treatment of primarily non-resectable adenocarcinoma of the rectum. Results from two consecutive studies. Eur J Cancer Clin Oncol 1989;25:1535-41.

[2] Sauer R, Becker H, Hohenberger W, et al. Preoperative versus postoperative chemoradiotherapy for rectal cancer. N Engl J Med 2004;351:1731-40.

[3] Sebag-Montefiore D. Developments in the use of chemoradiotherapy in rectal cancer. Colorectal Dis 2006;8:14-7.

[4] Improved survival with preoperative radiotherapy in resectable rectal cancer. Swedish rectal cancer trial. N Engl J Med 1997; 336: 980-987.

[5] Kapiteijn E, Marijnen CA, Nagtegaal ID, et al. Preoperative radiotherapy combined with total mesorectal excision for resectable rectal cancer. N Engl J Med 2001;345:638-46.

[6] Peeters KC, Marijnen CA, Nagtegaal ID, et al. The TME trial after a median follow-up of 6 years: increased local control but no survival benefit in irradiated patients with resectable rectal carcinoma. Ann Surg 2007;246:693-701.

[7] Miles KA. Perfusion CT for the assessment of tumour vascularity: which protocol? Br J Radiol 2003;76:S36-42.

[8] Goh V, Padhani AR, Rasheed S. Functional imaging of colorectal cancer angiogenesis. Lancet Oncol 2007;8:245-55.

[9] Sahani DV, Kalva SP, Hamberg LM, et al. Assessing tumor perfusion and treatment response in rectal cancer with multisection $\mathrm{CT}$ : initial observations. Radiology 2005;234:785-92.

[10] Bellomi M, Petralia G, Sonzogni A, Zampino MG, Rocca A. CT perfusion for the monitoring of neoadjuvant chemotherapy and radiation therapy in rectal carcinoma: initial experience. Radiology 2007;244:486-93.

[11] Park MS, Klotz E, Kim MJ, et al. Perfusion CT: noninvasive surrogate marker for stratification of pancreatic cancer response to concurrent chemo- and radiation therapy. Radiology 2009;250:110-7.
[12] Wang J, Wu N, Cham MD, Song Y. Tumor response in patients with advanced non-small cell lung cancer: perfusion CT evaluation of chemotherapy and radiation therapy. AJR Am J Roentgenol 2009;193:1090-6.

[13] Harvey C, Dooher A, Morgan J, Blomley M, Dawson P. Imaging of tumour therapy responses by dynamic CT. Eur J Radiol 1999;30:221-6.

[14] Tofts PS, Brix G, Buckley DL, et al. Estimating kinetic parameters from dynamic contrast-enhanced $\mathrm{T}(1)$-weighted MRI of a diffusable tracer: standardized quantities and symbols. J Magn Reson Imaging 1999;10:223-32.

[15] Aerts HJ, van Riel NA, Backes WH. System identification theory in pharmacokinetic modeling of dynamic contrast-enhanced MRI: influence of contrast injection. Magn Reson Med 2008;59:1111-9.

[16] Zima A, Carlos R, Gandhi D, Case I, Teknos T, Mukherji SK. Can pretreatment CT perfusion predict response of advanced squamous cell carcinoma of the upper aerodigestive tract treated with induction chemotherapy? AJNR Am Neuroradiol 2007;28:328-34.

[17] Hermans R, Lambin P, Van der Goten A, et al. Tumoural perfusion as measured by dynamic computed tomography in head and neck carcinoma. Radiother Oncol 1999;53:105-11.

[18] Hermans R, Van den Bogaert W. Outcome prediction after surgery and chemoradiation of head-and-neck squamous cell carcinoma (HNSCC), using baseline perfusion computed tomography (CT) microcirculatory parameters vs. tumor volume. Int J Radiat Oncol Biol Phys 2009;74:1307 [author reply 1307].

[19] Daisne JF, Sibomana M, Bol A, Doumont T, Lonneux M, Gregoire V. Tridimensional automatic segmentation of PET volumes based on measured source-to-background ratios: influence of reconstruction algorithms. Radiother Oncol 2003;69:247-50.

[20] Ollers M, Bosmans G, van Baardwijk A, et al. The integration of PET-CT scans from different hospitals into radiotherapy treatment planning. Radiother Oncol 2008;87:142-6.

[21] Harrer JU, Parker GJ, Haroon HA, et al. Comparative study of methods for determining vascular permeability and blood volume in human gliomas. Magn Reson Imaging 2004;20:748-57.

[22] Jackson A, Jayson GC, Li KL, et al. Reproducibility of quantitative dynamic contrast-enhanced MRI in newly presenting glioma. $\mathrm{Br} J$ Radio 2003;76:153-62.

[23] Walker-Samuel S, Leach MO, Collins DJ. Reference tissue quantification of DCEMRI data without a contrast agent calibration. Phys Med Bio 2007;52:589-601.

24] Goh V, Halligan S, Hugill JA, Gartner L, Bartram CI. Quantitative colorecta cancer perfusion measurement using dynamic contrast-enhanced multidetector-row computed tomography: effect of acquisition time and implications for protocols. J Comput Assist Tomogr 2005;29:59-63.

[25] Henderson E, Rutt BK, Lee TY. Temporal sampling requirements for the tracer kinetics modeling of breast disease. Magn Reson Imaging 1998;16:1057-73.

[26] Kierkels RG, Backes WH, Janssen MH, et al. Comparison between perfusion computed tomography and dynamic contrast-enhanced magnetic resonance imaging in rectal cancer. Int J Radiat Oncol Biol Phys 2009.

[27] Goh V, Halligan S, Gartner L, Bassett P, Bartram CI. Quantitative colorecta cancer perfusion measurement by multidetector-row CT: does greater tumour coverage improve measurement reproducibility? Br J Radiol 2006;79:578-83. 